\title{
Concurrent facilitation of food-reinforced, spaced licking and depression of schedule-induced, polydipsic licking by amphetamine ${ }^{1}$
}

\author{
EVALYN F. SEGAL ${ }^{2}$ AND DAVID L. ODEN ${ }^{3}$ \\ SAN DIEGO STATE COLLEGE
}

Two rats that were reinforced with food for spacing their water licks at least $20 \mathrm{sec}$ apart showed a licking pattern that alternated irregularly between low-rate (operant) licking and high-rate (polydipsic) licking. Intraperitoneal administration of $2 \mathrm{mg} / \mathrm{kg}$ of d,1-amphetamine sulfate just before a session caused the spaced, operant licking to increase in rate while at the same time the high-rate, polydipsic licking bursts decreased in duration and regularity.

Both increases and decreases in response output have been reported following the administration of amphetamine (Cole, 1967; Dews \& Morse, 1961; Hearst, 1961; Hearst \& Whalen, 1963; Poschel, 1963; Segal, 1962; Segal \& Deadwyler, 1964b; Segal, Oden, \& Deadwyler, 1965; Smith, 1967), but rarely have both effects been seen in the same organism at the same time. Exceptions are the report by Segal \& Deadwyler (1964b) that bar presses maintained by a spacedresponse (DRL) food reinforcement schedule increased under drug at the same time that collateral (polydipsic) water drinking decreased, and Smith's (1967) report that the lower response rate under concurrent two-key food reinforcement schedules tended to increase, while the higher response rate tended to decrease, under drug. In both of these cases, the responses that were differentially affected were emitted on spatially separated operanda, either a bar and a water tube or two pecking keys. The present report demonstrates that spatial separation of the responses is not necessary. Concurrent increases and decreases in responding can occur on one and the same operandum, so long as two functionally distinct forms of responding are involved.

Method

Two adult albino male rats, maintained at $80 \%$ of ad lib weight by food (but not water) deprivation, were reinforced for 20 days on a DRL (differential reinforcement of low rate) food schedule that reinforced licks at a water tube spaced $20 \mathrm{sec}$ or more apart. Prior to this procedure they had been reinforced for 20 days for bar presses spaced $20 \mathrm{sec}$ or more apart, and then for an additional 20 days for touches of a food cup spaced 20 sec or more apart (Segal, 1967). During these earlier procedures the water bottle that served as the operandum in the present experiment had not been present. Sessions lasted until 50 food pellets had been earned. The water bottle, and the food cup that delivered pellets, were on opposite walls of the conditioning chamber, which was enclosed in a sound-resistant, ventilated shell that contained white masking noise and constant illumination. Licks at the water bottle were sensed with a commercial drinkometer, and recorded on equipment in another room.

On the 21st day of the spaced licking procedure, $2 \mathrm{mg} / \mathrm{kg}$ of $\mathrm{d}, 1$-amphetamine sulfate dissolved in physiological saline were administered intraperitoneally immediately before the experimental session. The rats had not received any injections previously. Resulis

The top record of Fig. 1 shows the cumulative licks of one of the two Ss on the day preceding drug. Performance of the other rat was similar. Like other rats trained on spaced-licking schedules in our laboratory (Segal \& Deadwyler, 1964a), the licking performance alternated irregularly between spaced, low rate licks (as at $a$ in Fig. 1), under the control of the operant reinforcement schedule, and high rate licking bursts (as at b), under the control of the variables (whatever they may be) producing scheduleinduced polydipsia (see, for example, Falk, 1961; Schaeffer \& Diehl, 1966; Segal, 1965; Segal \& Holloway. 1963). The spaced-licking performance was quite efficient: Notice the close spacing of food reinforcements. High rate licks, of course, were ineffective in producing food.

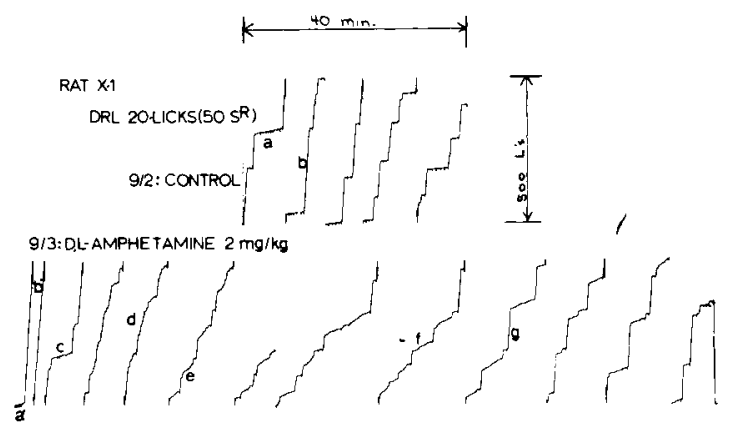

Fig. 1. Cumulative licks on the day preceding drug (top) and following drug injection (bottom), in rat X-1. Oblique deflections represent food reinforcements. 
The lower record of Fig. 1 shows the drugged performance. The session started with several spaced, reinforced licks, at $a^{\prime}$, followed by an unusually long burst of high rate licking, at $b^{\prime}$. (This long burst might have been an emotional effect of the novel injection procedure-on the hypothesis that polydipsic drinking is at least partly controlled by emotional variables.) Then, at $c$, spaced licking resumed, but at a higher rate than normal: Notice the wider spacing of reinforcements. Then came two high rate bursts separated by a very brief episode of what might have been spaced (but too rapid) licking, and then the licking pattern became highly irregular. In the section of the record between $c$ and $e$, it is difficult to decide whether the licking is speeded-up spaced licking or frequently interrupted polydipsic licking, but by e the two licking patterns drew clearly apart, and it is obvious that speeded-up spaced licking alternated irregularly with unusually brief bursts of high rate, polydipsic licking. By $f$ this pattern of alternation is clearer, and by $g$ the polydipsiclicking appeared to have recovered from the drug (bursts were smoother, less "grainy," and longer), while spaced licking continued at an abnormally high rate (few reinforcements) to the end of the session. The drugged performance of the other rat was similar.

\section{Discussion}

It is still uncertain when amphetamine can be expected to facilitate responding and when depress it. One view is that amphetamine depresses food and water motivation but stimulates motor behavior (Cole, 1967; Poschel, 1963), or at least, aversively-motivated behavior (Hearst, 1961). Another view is that amphetamine stimulates low rate behavior but depresses high rate behavior (Dews \& Morse, 1961).

Since it is not clear what causes schedule-induced polydipsia, one can only guess at the significance of the fact that amphetamine depresses polydipsic drinking (Segal \& Deadwyler, 1964b; Segal, Oden, \& Deadwyler, 1965; and the present results). In the absence of further evidence, it is prudent to favor the simplest interpretation, which is that polydipsic licking is depressed by amphetamine because it is high rate behavior, while spaced licking is stimulated by am- phetamine because it is low rate behavior.

Another intriguing possibility is that amphetamine differentially affects operantly controlled and emotionally and reflexively controlled drinking, but there is insufficient evidence for this idea as yet.

\section{References}

COLE, S. O. Experimental effects of amphetamine: a review. Psychol. Bull., 1967, 68, 81-90.

DEWS, P. B., \& MORSE, W. H. Behavioral pharmacology. Annu. Rev. Pharmacol, 1961, 1, 145-174.

FALK, J. L. Production of polydipsia in normal rats by an intermittent food schedule. Science, 1961, 133, 195-196.

HEARST, E. Effects of d-amphetamine on behavior reinforced by food and water. Psychol. Rep., 1961, 8, 301-309.

HEARST, E., \& WHALEN, R. E. Facilitating effects of d-amphetamine on discriminated avoidance performance. J. comp. physiol Psychol. 1963, 56, 124-128.

POSCHEI, B. P. H. Effects of methamphetamine on hunger and thirst motivated variable-interval performance. J. comp. physiol. Psychol, $1963,56,968-973$.

SCHAEFFER, R. W., \& DIEHL, JUDITH C. Collateral water drinking in rats maintained on FR food reinforcement schedules. Psychon. Sci, $1966,4,257-258$.

SEGAL, EVALYN F. Effects of dl-amphetamine under concurrent VI DRL reinforcement. J. exp. A nal. Beh., 1962, 5, 105-112.

SEGAL, EVALYN F. The development of water drinking on a dry-food free-reinforcement schedule. Psychon. Sci., 1965, 2, 29-30.

SEGAL, EVALYN F., \& DEADWYLER, S. A. Water drinking patterns under several dry food reinforcement schedules. Psychon. Sci, 1964, 1, 271-272a.

SEGAL, EVALYN F., \& DEADWYLER, S. A. Amphetamine differenti ally affects temporally spaced bar pressing and collateral water drinking. Psychon. Sci, 1964, 1, 349-350b.

SEGAL, EVALYN F., \& HOLLOWAY, S. M. Timing behavior in rats with water drinking as a mediator. Science, 1963, 140, 888-889.

SEGAL, EVALYN F., ODEN, D. L., \& DEADWYLER, S. A. Determinants of polydipsia: V. Effect of amphetamine and pentobarbital. Psychon. Sci., 1965, 3, 33-34.

SEGAL, EVALYN F. Transfer of timing behavior from one response to another. Paper read at the West. Psychol. Assoc. Conven., San Francisco, May, 1967.

SMITH, C. B. Relationship between rates of responding of pigeons on concurrent schedules of reinforcement and the behavioral effects of d-amphetamine, imipramine, and chlorpromazine. Paper read at the Sympo. Res. Concur. Beh., Amer. Psychol. Assoc. Conven., Wash. D. C., September, 1967.

Notes

1. Supported by Grants NSF GB 1605, NSF GB 5777, and NIMH 8505.

2. Present address: Dept. of Psychology, University of Illinois at Chicago Circle.

3. Present address: Dept. of Psychology, University of Pennsylvania. 